\title{
HOSPITAL LENGTH OF STAY PREDICTION BASED ON PATIENT EXAMINATION USING NEURAL NETWORK
}

\author{
Rabiatul Adawiyah' ${ }^{1}$, Tessy Badriyah ${ }^{2}$, Iwan Syarif ${ }^{3}$ \\ 1,2,3Politeknik Elektronika Negeri Surabaya, INDONESIA \\ Kampus PENS Jl. Raya ITS Sukolilo, Surabaya, 60111 \\ Email: ${ }^{1}$ wilyanyatul@gmail.com, 2tessy@pens.ac.id, 3iwanarif@pens.ac.id
}

\begin{abstract}
Length of stay (LOS) or length of stay is the main indicator in improving health services, which is expected to continue to increase along with population growth. The population of Indonesia is included in the largest category in the world. This was followed by an increase in the number of inpatient and emergency unit visits which had a high burden of care costs. This study aims to provide a solution by predicting LOS using Neural Network (NN). Predictions can be used as a consideration in improving effective and efficient health services. To improve the performance of the NN algorithm, we implement parameter optimization using the Grid Search to find the combination of the number of epochs, learning rate and momentum that can produce the best accuracy value. The results showed that NN could predict LOS with an accuracy rate of $89.22 \%$ when using the default parameter. Meanwhile, by performing parameter optimization using the Grid Search to find the ideal combination of parameters for learning rate, momentum and epoch, the accuracy rate is increased to $92.20 \%$.
\end{abstract}

Keywords: length of stay, neural network, patient examination, machine learning

\begin{abstract}
Abstrak
Length of stay (LOS) atau lama rawat inap merupakan indikator utama dalam peningkatan pelayanan kesehatan yang diperkirakan akan terus meningkat bersamaan dengan jumlah pertumbuhan penduduk. Jumlah penduduk Indonesia termasuk dalam kategori terbanyak di dunia. Hal ini diikuti dengan pertambahan jumlah kunjungan pasien rawat inap dan unit gawat darurat yang memiliki beban biaya perawatan yang tinggi. Penelitian ini bertujuan untuk memberikan solusi dengan melakukan prediksi LOS menggunakan Neural Network (NN). Prediksi dapat digunakan sebagai pertimbangan dalam peningkatan pelayanan kesehatan yang efektif dan efisien. Untuk meningkatkan performansi dari algoritma NN, kami menerapkan optimasi parameter menggunakan Grid Search untuk menemukan kombinasi jumlah epoch, learning rate dan momentum yang dapat menghasilkan nilai akurasi terbaik. Hasil penelitian menunjukkan bahwa NN dapat memprediksi LOS dengan tingkat akurasi 89,22\% jika menggunakan default parameter. Sedangkan dengan melakukan optimasi parameter menggunakan Grid Search untuk menemukan kombinasi ideal parameter learning rate, momentum dan epoch, maka tingkat akurasi meningkat menjadi $92,20 \%$.
\end{abstract}

Kata kunci: length of stay, neural network, patient examination, machine learning 


\section{PENDAHULUAN}

Length of stay (LOS) atau Lama Rawat Inap merupakan jumlah total hari seorang pasien dirawat di rumah sakit. Dimulai dari hari pertama masuk (tanggal masuk) sampai dengan pasien selesai dirawat (tanggal keluar) untuk dilanjutkan rawat jalan, sudah sembuh total atau tidak tertolong jiwanya (meninggal). LOS begitu bermanfaat bagi pengelolaan rumah sakit yang dalam peningkatan pelayanan kesehatan yang efektif dan efisien berdasarkan jumlah penduduk yang terus berkembang[1].

Perserikatan Bangsa Bangsa (PBB) pada tahun 2015 dalam The 2015 Revision of World Population Prospects melaporkan populasi dunia diperkirakan akan mencapai 8,5 miliar pada tahun 2030, kemudian akan meningkat menjadi 9,7 miliar pada tahun 2050, dan melampaui 11 miliar pada tahun 2100. Indonesia termasuk dalam kategori negara dengan tingkat pertumbuhan penduduk terbesar di dunia[2]. Hal ini berkaitan dengan peningkatan beberapa faktor yang memiliki pengaruh terhadap pertumbuhan penduduk antara lain yakni peningkatan angka kelahiran, persebaran penduduk yang tidak merata dan terjadi penurunan angka kematian setiap tahun. Peningkatan ini diiringi dengan pertambahan jumlah kunjungan pasien di rumah sakit, seperti rawat jalan, rawat inap dan unit gawat darurat. Maka dari itu, rumah sakit harus siap dalam memberikan fasilitas dan alat penunjang pelayanan[3], terutama pelayanan length of stay pasien. Hal ini didukung dengan terjadinya tingkat LOS di negara eropa diperkirakan mencatat pemulangan tertinggi untuk semua pasien rawat di rumah sakit (42.919 per 100.000) penduduk untuk pasien rawat inap pada tahun 2018[4]. LOS atau lama rawat inap seringkali menjadi indikator utama dalam peningkatan pelayanan kesehatan yang efisien, hal ini diakui bahwa masa tinggal yang lebih singkat menunjukkan sumber daya yang efektif[5], secara khusus rawat inap berkaitan dengan beban biaya perawatan yang signifikan sering terjadi pada pasien dewasa maupun anak-anak, disebabkan oleh infrastruktur kesehatan yang menjadi faktor resiko peningkatan LOS. Maka dari itu, penting untuk memberi arahan agar bisa mengurangi LOS tanpa mengorbankan hasil dan kualitas kesehatan dengan mengindikasi prediksi LOS pada pasien[6]. Sehingga prediksi lama rawat inap (LOS) merupakan masalah yang dapat diselesaikan oleh metode statistika atau prediksi berbasis kecerdasan buatan (AI) yang berkembang biak dalam beberapa tahun terakhir. AI memberikan layanan kesehatan yang hemat biaya dan mengelola dengan efektif dan efisien[7].

Neural Network dalam bidang kesehatan sudah mulai berkembang dengan sangat pesat. Ada beberapa penelitian yang menggabungkan neural network dengan machine learning dalam melakukan identifikasi LOS pasien di rumah sakit. Hal ini bisa dilihat setelah melakukan peningkatan kinerja NN secara berulang, sehingga diperoleh hasil prediksi yang lebih akurat dari model regresi logistic[5]. Penelitian lain juga menunjukkan bahwa rata-rata prediksi LOS menggunakan neural network tidak berbeda secara signifikan dari rata-rata LOS aktual[8]. Penelitian sebelumnya menjelaskan bahwa LOS sangat bermanfaat bagi pengelolaan rumah sakit. Misalnya, perkiraan akurasi LOS, sehingga rumah sakit dapat merencanakan pengelolaan tempat tidur yang tersedia dengan lebih baik dan sumber daya yang efisien[1]. Penelitian ini menjelaskan Length of stay (LOS) memiliki keterkaitan dengan faktor 
demografi pasien, manajemen perawatan, renspon terhadap pengobatan dan data administrasi[9]. Hal ini berarti, bahwa durasi rawat inap yang lebih singkat dari seharusnya menjadi indikator rumah sakit untuk menurunkan biaya dan peningkatan keuntungan dengan memulangkan pasien lebih cepat. Sehingga durasi LOS digunakan sebagai indikator kinerja rumah sakit dan ukuran pemanfaatan sumber daya. Di sisi lain, durasi perawatan yang panjang bisa disebabkan oleh layanan kesehatan yang kurang efektif dan efisien. Sehingga durasi perawatan bisa menjadi sebab dan akibat dari kualitas layanan yang buruk, ketidak jelasan ini memberi sebab bahwa perlu indikator tambahan untuk mengukur kualitas pelayanan kesehatan[10]. Sehingga, penerapan pelayanan kesehatan, khususnya pelayanan length of stay di rumah sakit, diperlukan sumber daya manusia atau tenaga ahli yang memiliki keahlian terutama dalam bidang komputer dan analisis data. Kompleksitas yang tinggi dalam melakukan prediksi length of stay di rumah sakit sering kali menjadi kendala bagi pihak rumah sakit ataupun tenaga medis pemula yang ingin menerapkan pelayanan length of stay pada lingkungan rumah sakit atau pasien di indonesia. Pasien yang memiliki Length of Stay (LOS) tentu sangat bervariasi dengan Faktor prediktor yang mempengaruhi LOS dapat berupa karakteristik pasien, keadaan klinis, tindakan medis, pengelolaan pasien di ruangan maupun masalah adminstrasi rumah sakit. Durasi LOS adalah sesuatu yang penting dalam akses layanan kesehatan yang diperkirakan akan meningkat pada tahun yang akan datang seiring pertambahan penduduk.

Penelitian ini bertujuan untuk membangun sebuah sistem prediksi length of stay menggunakan neural network. Sistem yang dibangun dapat dimanfaatkan sebagai pertimbangan dalam peningkatan pelayanan kesehatan yang efektif dan efisien serta pertimbangan dalam perkiraan sumber daya yang lebih baik. Fitur yang digunakan untuk proses prediksi yaitu diperoleh dari data demografi, manajemen perawatan, respon terhadap perawatan dan data administrasi yang terdapat dalam data pasien LOS.

\section{METODOLOGI PENELITIAN}

Adapun desain sistem secara keseluruhan dari penelitian yang akan dibangun ditunjukkan pada gambar 1 . 


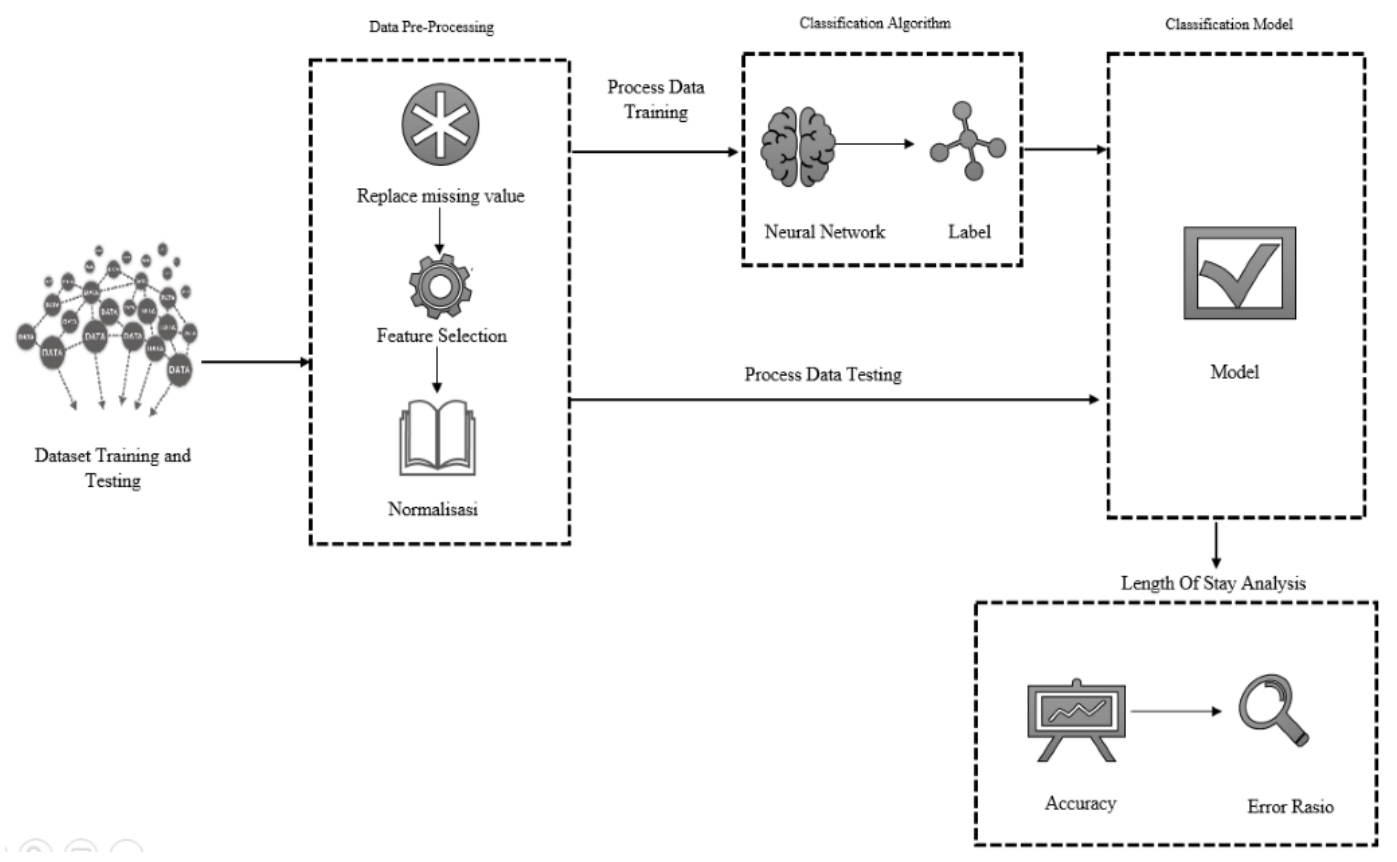

Gambar 1. Desain Sistem

Desain sistem terbagi atas dua ruang lingkup kerja, Input data dan analisa Output. Dimana model memerlukan input dari dataset yang hendak dilakukan pembagian data yaitu training 30\% dan testing 70\%. Data ini memerlukan proses hingga mendapatkan model prediksi, selanjutnya melakukan analisis hasil.

Dari gambaran besar desain sistem, proses dari penelitian ini dibagi kedalam empat bagian inti yang antara lain yaitu Tahapan Pre-processing untuk manipulasi dataset sebelum dilakukan input data kedalam model dengan tujuan agar kompatibel dengan library yang digunakan, Tahapan klasifikasi digunakan untuk mengenali, mempelajari dan mengetahui hubungan antara atribut dengan label atribut. Tahapan model yaitu membangun algoritma yang dapat memberikan petunjuk dalam mencari korelasi. serta tahapan length of stay analisis yaitu tahapan melakukan analisis korelasi yang berhasil model dapatkan berupa akurasi dan error rasio.

\subsection{Dataset}

Pada penelitian ini, data yang diperoleh diambil dari laman kaggle ${ }^{1}$. dimana data memiliki jumlah dimensi 28 atribut, termasuk atribut class atau label, 9 atribut nominal dan 19 atribut numerik. Data Kemudian akan dilakukan proses pemilihan fitur sehingga data menjadi 22 atribut yang berhasil terpilih dengan jumlah data 5000 record. Atribut yang terpilih yaitu, gender, age, LOSdays, Admit_type, Admit_Location, Insurance, Ethnicity, Num_Callouts, Num_diagnosis, Num_procs, Admit_procedure, Num_CPTevents, Num_input, Num_Labs, Num_Microlabs,

\section{${ }^{1}$ https://www.kaggle.com/drscarlat/mimic3d}


Num_Notes, Num_Output, Num_Rx, Num_ProcEvents, Num_Transfers, Num_chartEvent, Expired_Hospital, TotalNumInteract, LOS_groupNum.

\subsection{Evaluasi Model}

Berikut ini akan dijelaskan formula yang digunakan pada metrik pengukuran performansi yang digunakan pada penelitian ini.

\section{a. Root Mean Square Error}

Digunakan RMSE untuk mengevaluasi model. Cara ini juga dikenal dengan nama root mean squared Eror (RMSE) yaitu dengan menguadratkan error (predicted-observed) dibagi dengan jumlah data (= rata-rata), lalu diakarkan. Secara matematis, rumusnya ditulis sebagai berikut:

$R M S E=1 n \sum 1=1 n\left(y i^{\prime}-y i\right) 2$

b. Confusion Matrix

Pengukuran hasil kinerja dilakukan dengan Confussion Matrix, akurasi dan error sebagai kriteria evaluasi. Kriteria tersebut disajikan dalam table yang disebut dengan Confussion Matrix yang ditujukkan pada tabel 1.

Tabel 1. Confussion Matrix

$\begin{array}{lll} & \text { Positive Actual } & \text { Negative Actual } \\ \text { Positive Predicted } & \text { TP (True Positif) } & \text { FP (False Positif) } \\ & & \text { Type I Error } \\ \text { Negative Predicted } & \text { FN (False Negative) } & \text { TN (True Negative) } \\ & \text { Type II Error } & \end{array}$

Dalam mengukur kinerja dengan menggunakan Confussion Matrix terdapat empat istilah yaitu TP, TN, FP, FN. TP adalah True Positive, yaitu banyaknya data positif yang diklasifikasikan dengan benar oleh sistem. TN adalah True Negative, yaitu jumlah data negatif yang diklasifikasikan dengan benar oleh sistem. Sedangkan FN adalah False Negative, yaitu banyaknya data positif yang terdeteksi sebagai data negatif oleh sistem. FP adalah False Positive, yaitu jumlah data negative yang terdeteksi sebagai data positif oleh sistem[11].

Setelah membuat confussion matrix, selanjutnya matrix evaluasi yang secara umum dapat diketahui sebagai berikut[11]:

Akurasi Merupakan persentase aplikasi yang diklasifikasikan dengan benar dibandingkan dengan jumlah total dalam sistem[11].

Accuracy $=T P+F N T P+T N+F P+F N \times 100 \%$

Error Rate atau tingkat kesalahan, beberapa penulis mengukur tingkat kesalahan dalam mendeteksi dalam sistem[11].

$E r r=F P+F N F P+T N+T P+F N \times 100 \%$ 


\section{HASIL DAN PEMBAHASAN}

Berdasarkan percobaan yang telah kami lakukan dari beberapa tahapan yaitu, Tahapan data Pre-Processing, Tahapan pembagian data training $70 \%$ dan data testing 30\%, tahapan klasifikasi prediksi menggunakan neural network, Tahapan model yaitu membangun algoritma yang dapat memberikan petunjuk dalam mencari korelasi, serta tahapan length of stay analisis. Pada tahapan klasifikasi dengan neural network menghasilkan karakteristik data dengan 4 label yaitu 0 sebagai LOS rendah, 1 sebagai LOS sedang, 2 sebagai LOS tinggi dan 3 sebagai LOS sangat tinggi. selanjutnya akan membahas mengenai pengujian arsitektur neural network menggunakan default parameter dan Hyperparameter Grid Search untuk meningkatkan kinerja.

Pengujian ini menggunakan pengukuran akurasi sebagai performansi, dengan melakukan perbandingan antara hasil default parameter dan Hyperparameter Grid search berdasarkan jumlah epoch, learning rate dan momentum dengan jumlah kelipatan 9. Pengujian jumlah epoch bertujuan untuk mencari jumlah epoch yang optimal berdasarkan hasil akurasi yang diperoleh dari NN. Jumlah epoch yang ditetapkan mulai dari 200 untuk default parameter dan Hyperparameter Grid search, Learning rate mulai dari 0.01 - 0.09 dan momentum 0.1-0.9.

\subsection{Pengukuran Akurasi Pada default parameter berdasarkan Jumlah Epoch, Learning Rate Dan Momentum}

Hasil pengukuran Akurasi pada default parameter berdasarkan jumlah epoch, learning rate dan momentum ditunjukkan pada tabel 2.

Tabel 2. Hasil default parameter berdasarkan Jumlah epoch, learning rate dan momentum

\begin{tabular}{lllll}
\hline \multirow{2}{*}{$\begin{array}{c}\text { Percobaan } \\
\text { ke-i }\end{array}$} & Epoch & $\begin{array}{c}\text { Learning } \\
\text { rate }\end{array}$ & Momentum & Akurasi \\
\cline { 2 - 5 } & 200 & 0.01 & 0.9 & $89.11 \%$ \\
2 & 200 & 0.02 & 0.8 & $88.91 \%$ \\
3 & 200 & 0.03 & 0.7 & $88.74 \%$ \\
4 & 200 & 0.04 & 0.6 & $88.51 \%$ \\
5 & 200 & 0.05 & 0.5 & $87.97 \%$ \\
6 & 200 & 0.06 & 0.4 & $88.57 \%$
\end{tabular}




\begin{tabular}{lllll}
\hline \multirow{2}{*}{$\begin{array}{c}\text { Percobaan } \\
\text { ke-i }\end{array}$} & Epoch & $\begin{array}{c}\text { Learning } \\
\text { rate }\end{array}$ & Momentum & Akurasi \\
\cline { 2 - 5 } & 200 & 0.07 & 0.3 & $89.08 \%$ \\
7 & 200 & 0.08 & 0.2 & $89.14 \%$ \\
8 & 200 & 0.09 & 0.1 & $89.22 \%$ \\
\hline
\end{tabular}

Hasil menunjukkan bahwa pada jumlah epoch 200, learning rate 0.09 dan momentum 0.1 nilai akurasi meningkat.

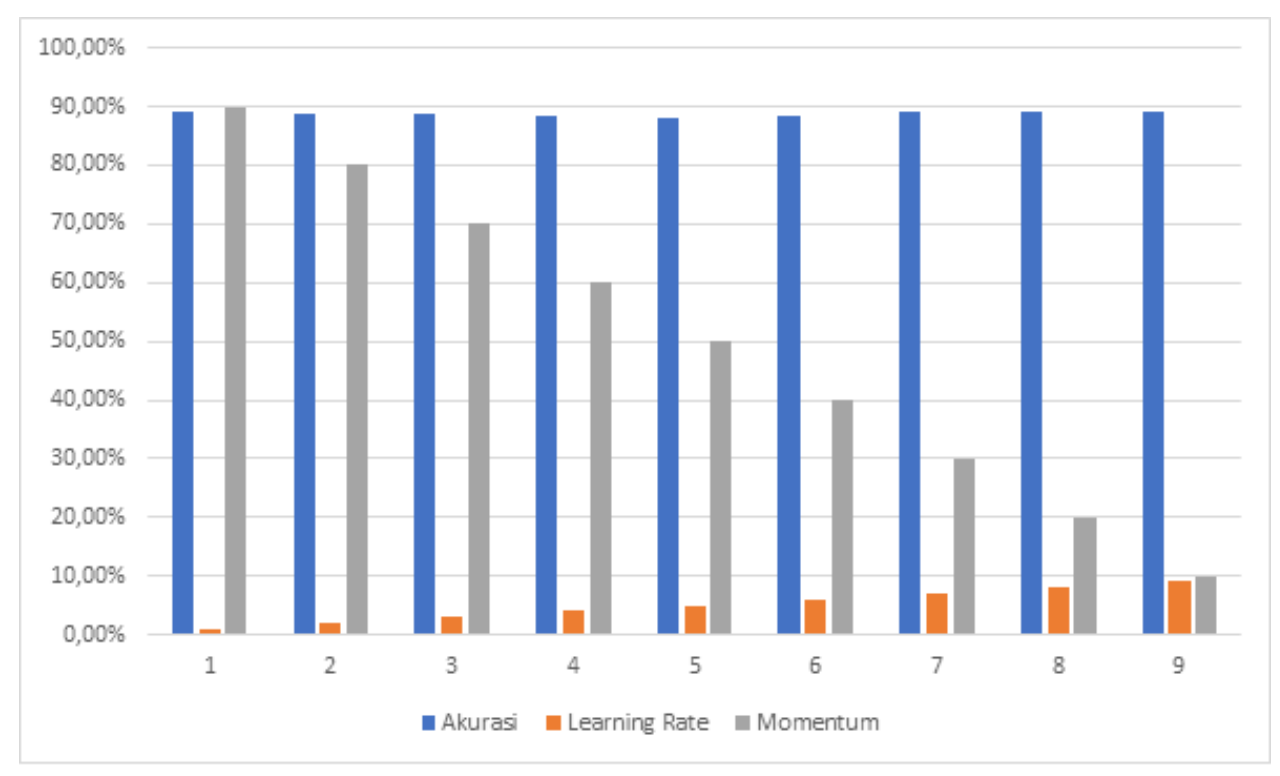

Gambar 2, Hasil grafik dari pengujian default parameter, akurasi (biru), learning rate (orange) dan momentum (silver).

Hasil percobaan dengan epoch 200, learning rate 0.09 dan momentum 0.1 memberikan hasil akurasi lebih baik diantara percoban lain dengan nilai akurasi $89.22 \%$.

\subsection{Pengukuran Akurasi Pada Hyperparameter Grid Search berdasarkan Jumlah Epoch, Learning Rate Dan Momentum}

Adapun Hasil pengukuran Akurasi pada Hyperparameter Grid Search berdasarkan jumlah epoch, learning rate dan momentum. Jumlah epoch yang ditetapkan mulai dari 200, Learning rate mulai dari batas bawah 0.01, batas atas 0.9, step 5, scale yang digunakan linear dan momentum mulai dari batas bawah 0.1, batas atas 0.9 , step 5 , scale yang digunakan linear, ditunjukkan pada tabel 3 . 
Tabel 3. Hasil default parameter berdasarkan Jumlah epoch, learning rate dan momentum

\begin{tabular}{lllll}
\hline \multirow{2}{*}{$\begin{array}{l}\text { Percobaan } \\
\text { ke-i }\end{array}$} & Epoch & Learning rate & Momentum & Akurasi \\
\cline { 2 - 5 } 1 & 200 & 0.01 & 0.9 & $92.08 \%$ \\
2 & 200 & 0.02 & 0.8 & $92.08 \%$ \\
3 & 200 & 0.03 & 0.7 & $92.08 \%$ \\
4 & 200 & 0.04 & 0.6 & $91.80 \%$ \\
5 & 200 & 0.05 & 0.5 & $92.20 \%$ \\
6 & 200 & 0.06 & 0.4 & $92.20 \%$ \\
7 & 200 & 0.07 & 0.3 & $92.20 \%$ \\
8 & 200 & 0.08 & 0.2 & $92.16 \%$ \\
9 & 200 & 0.09 & 0.1 & $92.16 \%$ \\
\hline
\end{tabular}

Hasil menunjukkan bahwa pada jumlah epoch 200, learning rate 0.05-0.07, step 5, scale yang digunakan linear dan momentum $0.5-0.3$, step 5 , scale yang digunakan linear, nilai akurasi meningkat.

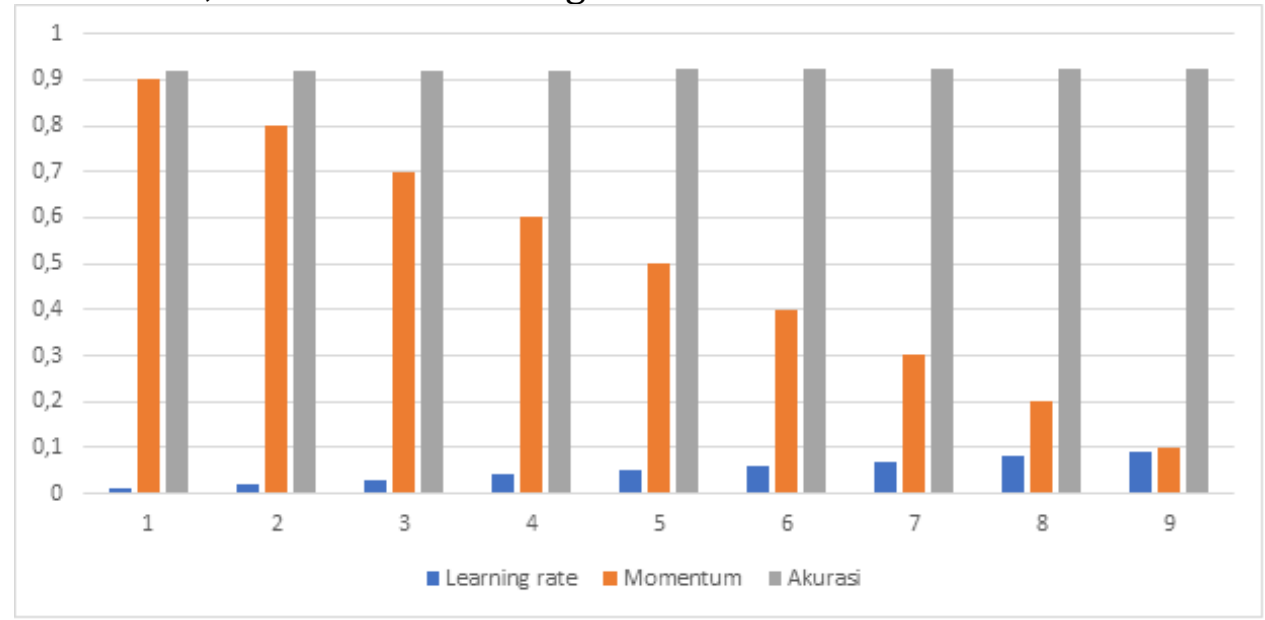

Gambar 3, Hasil grafik dari pengujian Hyperparameter Grid Search, akurasi (silver), learning rate (biru) dan momentum (orange). 
Hasil percobaan dengan epoch 200, learning rate $0.05-0.07$, step 5, scale yang digunakan linear dan momentum 0.5-0.3, step 5, scale yang digunakan linear, memberikan hasil akurasi lebih baik diantara percoban lain dengan nilai akurasi menjadi $92.20 \%$.

\section{ANALISIS HASIL}

Hasil pengukuran Akurasi pada perbandingan default parameter dan Hyperparameter Grid Search, dapat diketahui bahwa, pengukuran Akurasi pada default parameter berdasarkan jumlah epoch, learning rate dan momentum. Jumlah epoch yang ditetapkan mulai dari 200 untuk default parameter, Learning rate mulai dari 0.01 - 0.09 dan momentum 0.1-0.9. Hasil menunjukkan pada jumlah epoch 200, learning rate 0.09 dan momentum 0.1 nilai akurasi meningkat dengan hasil akurasi lebih baik diantara percoban lain dengan nilai akurasi $89.22 \%$. Adapun pengukuran Akurasi pada Hyperparameter Grid Search berdasarkan jumlah epoch, learning rate dan momentum. Jumlah epoch yang ditetapkan mulai dari 200, Learning rate mulai dari batas bawah 0.01, batas atas 0.9 , step 5, scale yang digunakan linear dan momentum mulai dari batas bawah 0.1 , batas atas 0.9 , step 5 , scale yang digunakan linear. Hasil menunjukkan bahwa pada jumlah epoch 200, learning rate 0.05-0.07, step 5, scale yang digunakan linear dan momentum 0.5-0.3, step 5, scale yang digunakan linear, nilai akurasi meningkat dengan hasil akurasi lebih baik diantara percoban lain dengan nilai akurasi menjadi $92.20 \%$.

Berdasarkan hasil pengukuran akurasi perbandingan default parameter dan Hyperparameter Grid Search, dapat diambil simpulan bahwa jumlah epoch yang digunakan memiliki pengaruh dalam tingkat akurasi yang didapatkan, dengan jumlah epoch yang ditetapkan pada default parameter dan Hyperparameter Grid Search adalah 200. Berbeda dengan learning rate, semakin kecil jumlah learning rate maka nilai akurasi meningkat untuk default parameter, dan peningkatan terjadi pada learning rate 0.05-0.07 dengan batas bawah 0.01, batas atas 0.9, step 5, scale yang digunakan linear untuk Hyperparameter Grid Search. Sama halnya dengan jumlah momentum, semakin kecil nilai momentum maka nilai akurasi meningkat untuk default parameter dan peningkatan terjadi pada momentum 0.5-0.3 dengan batas bawah 0.1 , batas atas 0.9 , step 5 , scale yang digunakan linear.

Adapun rekapitulasi hasil pengujian akurasi perbandingan default parameter dan Hyperparameter Grid Search ditunjukkan pada tabel 4, tabel 4 menunjukkan hasil pengujian yang unggul pada setiap percobaan.

Tabel 4. Rekapitulasi Hasil Pengujian Akurasi

\begin{tabular}{llll}
\hline parameter & Pengujian & $\begin{array}{l}\text { Jumlah } \\
\text { percobaan }\end{array}$ & Akurasi \\
\hline $\begin{array}{l}\text { Default } \\
\text { Parameter }\end{array}$ & Epoch & 200 & $89.22 \%$
\end{tabular}




\begin{tabular}{llll}
\hline parameter & Pengujian & $\begin{array}{l}\text { Jumlah } \\
\text { percobaan }\end{array}$ & Akurasi \\
\hline & Learning rate & 0.09 & \\
& Momentum & 0.1 & \\
Hyperparameter & Epoch & 200 & $92.16 \%$
\end{tabular}

Grid Search

$\begin{array}{ll}\text { Learning rate } & 0.05-0.07 \\ \text { Momentum } & 0.5-0.3\end{array}$

Penggunaan dataset LOS memberikan hasil efektif dan efesien Ketika dilakukan klasifikasi menggunakan neural network, dilihat dari nilai akurasi yang di peroleh Hyperparameter Grid Search berdasarkan jumlah epoch, learning rate dan momentum dengan hasil akurasi $92.20 \%$. Hasil menunjukkan bahwa hyperparameter grid search memberikan pengaruh terhadap output model atau akurasi, selain memberikan pengaruh terhadap peningkatan akurasi, hyperparameter grid search dapat menentukan bagaimana parameter diinisialisasi dan diperbarui selama optimisasi. Sehingga peningkatan terjadi pada proses hyperparameter grid search, dimana grid akan melakukan pencarian pada seluruh kombinasi Learning rate mulai dari batas bawah 0.01 , batas atas 0.9 ukuran Learning rate, step 5, scale yang digunakan linear dan pencarian pada seluruh kombinasi momentum mulai dari batas bawah 0.1 , batas atas 0.9 , step 5 , scale yang digunakan linear. Hasil menunjukkan bahwa Hyperparameter Grid Search memilih kombinasi terbaik dari Learning rate dan momentum. dengan default parameter ukuran nilai pada parameter sudah ditentukan terlebih dahulu, sehingga tidak membutuhkan proses pencarian kombinasi nilai optimal dari parameter. Sehingga perbedaan hasil akurasi yang diperoleh Hyperparameter grid search dan default parameter diperanguhi oleh kombinasi nilai optimal.

\section{SIMPULAN}

Lama Rawat Inap (Length of Stay atau LOS) merupakan indikator utama dalam peningkatan pelayanan kesehatan yang efektif dan efisien. Penelitian ini bertujuan untuk menerapkan algoritma Neural Network (NN) untuk memprediksi Lama Rawat Inap. Hasil percobaan NN menggunakan default parameter adalah $89,22 \%$. Salah satu strategi untuk meningkatkan akurasi pada algoritma NN adalah dengan cara menemukan kombinasi terbaik untuk tiga parameter utama yaitu learning rate, momentum dan epoch yaitu menggunakan Grid Search. Dengan menggunakan Grid Search untuk melakukan optimasi parameter, akurasi NN meningkat menjadi 9 [1]2,20\%.

\section{DAFTAR PUSTAKA}

[1] N. Caetano, P. Cortez, and R. M. S. Laureano, "Using data mining for prediction of hospital length of stay: An application of the CRISP-DM methodology," Lect. Notes Bus. Inf. Process., vol. 227, pp. 149-166, 2015, doi: 10.1007/978-3-319- 


\section{8-3_9.}

[2] M. A. Umar, "Bonus Demografi Sebagai Peluang Dan Tantangan Di Era Otonomi Daerah," Genta Mulia, vol. 8, no. 2, pp. 90-99, 2020.

[3] W. M. Baihaqi, M. Dianingrum, and K. A. N. Ramadhan, "Regresi Linier Sederhana Untuk Memprediksi Kunjungan Pasien di Rumah Sakit Berdasarkan Jenis Layanan dan Umur Pasien," J. SIMETRIS, vol. 10, no. 2, pp. 671-680, 2019.

[4] Eurostat, "Hospital discharges and length of stay statistics." p. 14, 2015, [Online]. Available: http://ec.europa.eu/eurostat/statisticsexplained/index.php/Hospital_discharges_and_length_of_stay_statistics.

[5] P. F. J. Tsai et al., "Length of Hospital Stay Prediction at the Admission Stage for Cardiology Patients Using Artificial Neural Network," J. Healthc. Eng., vol. 2016, 2016, doi: 10.1155/2016/7035463.

[6] A. Cedars, L. Benjamin, S. V. Burns, E. Novak, and A. Amin, "Clinical predictors of length of stay in adults with congenital heart disease," Heart, vol. 103, no. 16, pp. 1258-1263, 2017, doi: 10.1136/heartjnl-2016-310841.

[7] C. S. Yang, C. P. Wei, C. C. Yuan, and J. Y. Schoung, "Predicting the length of hospital stay of burn patients: Comparisons of prediction accuracy among different clinical stages," Decis. Support Syst., vol. 50, no. 1, pp. 325-335, 2010, doi: 10.1016/j.dss.2010.09.001.

[8] C. Gholipour, F. Rahim, A. Fakhree, and B. Ziapour, "Using an artificial neural networks (ANNS) model for prediction of intensive care unit (ICU) outcome and length of stay at hospital in traumatic patients," J. Clin. Diagnostic Res., vol. 9, no. 4, pp. 19-23, 2015, doi: 10.7860/JCDR/2015/9467.5828.

[9] I. K. Lubis and S. Susilawati, "Analisis Length Of Stay (Los) Berdasarkan Faktor Prediktor Pada Pasien DM Tipe II di RS PKU Muhammadiyah Yogyakarta," J. Kesehat. Vokasional, vol. 2, no. 2, p. 161, 2018, doi: 10.22146/jkesvo.30330.

[10] F. E. B. Setyawan and S. Supriyanto, "Mutu Pelayanan Kesehatan," Manajemen Rumah Sakit. 2019.

[11] V. Kotu and B. Deshpande, "Model Evaluation," Predict. Anal. Data Min., pp. 257-273, 2015, doi: 10.1016/b978-0-12-801460-8.00008-2. 